\title{
Determination of friction coefficient between glass fiber and the concrete Fri (GF.C)
}

\author{
Amjad Khabaz \\ Department of Civil and Environmental Engineering, College of Engineering, Majmaah University, Riyadh, Kingdom of Saudi Arabia
}

Email address:

a.khabaz@mu.edu.sa,a.khabaz@hotmail.com

\section{To cite this article:}

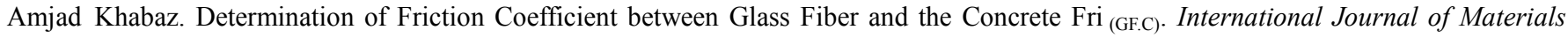
Science and Applications. Vol. 3, No. 6, 2014, pp. 321-324. doi: 10.11648/j.ijmsa.20140306.17

\begin{abstract}
The friction forces between glass fiber and the concrete in the case of Fiber Reinforced Concrete F.R.C are considered as the main factor to generate the bonding between these two building construction materials. In the case of using glass fiber as reinforcement material to improve the resistance capacity of plain concrete under an axial or flexural tension forces, bonding forces at the interface between the glass fiber and the concrete matrix must be satisfactory. Bonding forces between these two materials are generated due to friction forces at the interface; therefore the final evaluation of the bonding forces is related with the real value of the friction forces, consequently the friction coefficient value between glass fiber and the concrete is important to evaluate and calculate the real value of friction forces. This paper is devoted to introduce an experimental studies about the mechanism of glass fiber removing from concrete matrix which are named (pull-out tests) as well as a programming simulations prepared to represent this mechanism too, theses laboratory experiments and computer simulations have been used in determination process of the friction coefficient value between the glass fiber and the concrete matrix Fri (GF.C).
\end{abstract}

Keywords: Fiber Reinforced Concrete (FRC), Glass Fiber, Friction Coefficient Fri ${ }_{(\mathrm{GF.C})}$, Concrete Matrix, Pull-Out Test

\section{Introduction}

Determination of friction coefficient between glass fiber and the concrete needs to apply special procedures which might be divided into two directions, where the first direction is laboratory experiments of pull-out tests of single glass fiber embedded into concrete matrix as real samples using special metallic moulds, therefore these pull-out tests need precise ways to be able to prepare various samples under special conditions and moulds to keep the single glass fiber without any damage during the preparation process of these precise concrete samples (see Fig 1.1, 1.2), whereas the second direction is programming simulations as virtual samples using finite element method to represent the mechanism of single glass fiber removing process from concrete matrix under special conditions, where these virtual samples simulate the previous experimental program in the first direction of pull-out tests of that real concrete samples (see Fig 1.3).

Lab pull-out experiments results give a real description of single glass fiber displacements under the influence of external applied load as tension forces, where sliding part of force-displacement curve will be used to determine the friction coefficient, whereas programming simulations are used to obtain several force-displacement curves using various expected values of friction coefficient between glass fiber and the concrete.

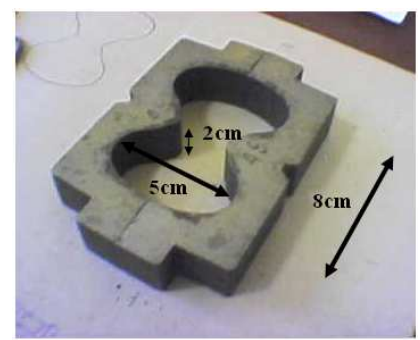

Figure 1.1. Steel mould used to prepare pull-out sample [1].

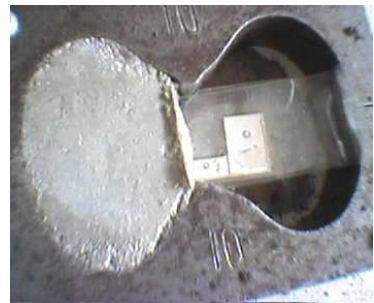

Figure 1.2. Finite element model of pull-out simulation [1]. 
Conformity between the results of laboratory pull-out tests and several force-displacement curves of programming simulations the right value of friction coefficient between glass fiber and the concrete can be found [1].

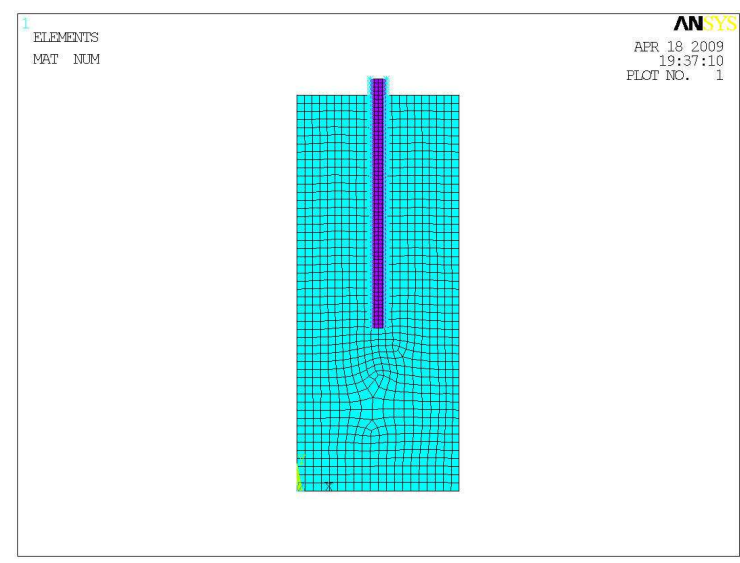

Figure 1.3. Finite element model of pull-out simulation [1].

\section{Materials and Methods}

\subsection{Pull-Out Test Stages}

Pull-out test can be divided into three stages (see Fig 2.1.1), the first stage represents the case of perfect adhesion mode where the bonding forces resist the applied tension load which is trying to extract the fiber from the concrete (see Fig 2.1.2), second stage might be named as debonding stage starts when the tension applied load reaches critical value where the bonding strength starts to diminish; then partial debonding progressively appears at the interface (see Fig 2.1.3) until full interfacial debonding situation happens; then the third pull-out stage starts where the frictional sliding mode can be shown (see Fig 2.1.4), this third stage is necessary to calculate the friction factor during the outwards-sliding motion of the fiber from the concrete matrix. Therefore we will choose an experimental single glass fiber pull-out curve and also prepare suitable programming simulations using different values of friction coefficient, from experiments and simulations various force-displacement curves will be obtained, then conformity between the experimental results and programming simulations will lead to fond the right value of friction coefficient between glass fiber and the concrete.

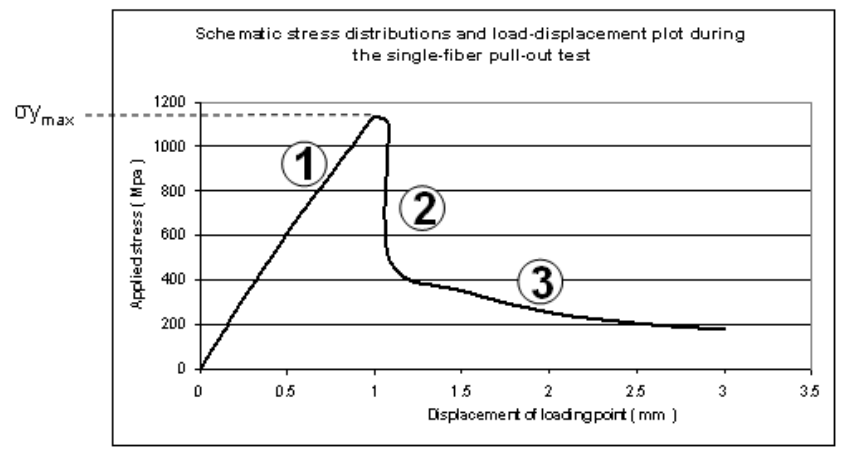

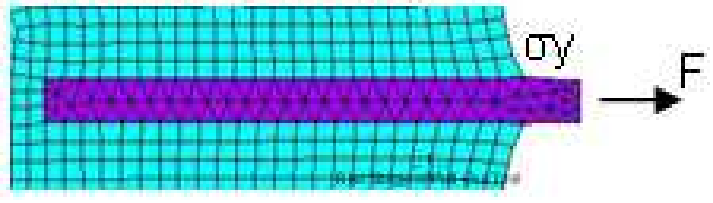

Figure 2.1.2. First stage of pull-out test (perfect adhesion).

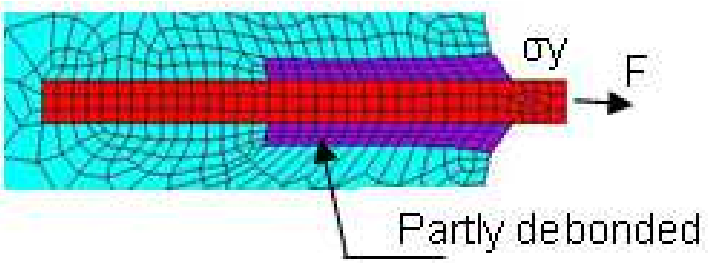

Figure 2.1.3. Second stage of pull-out test (partial debonding).

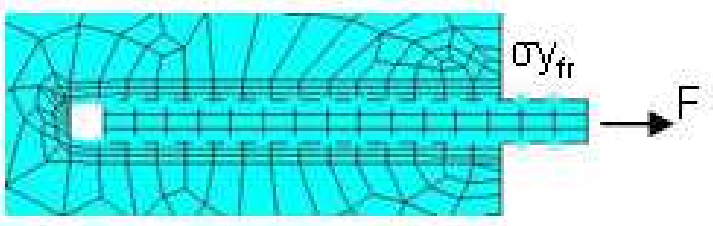

Figure 2.1.4. Third stage of pull-out test (frictional sliding).

\subsection{Experimental Pull-Out Test Results}

An experimental sample of single glass fiber is prepared in the lab, where this single glass fiber is embedded $2 \mathrm{~cm}$ into concrete matrix, where the concrete matrix is prepared according to concrete mix components as shown in the table 2.2.1.

Table 2.2.1. Components of the concrete matrix used in pull-out tests

\begin{tabular}{lll}
\hline \multirow{2}{*}{ Designation: } & \multicolumn{2}{l}{ F50a GLASS FIBER } \\
\cline { 2 - 3 } Components & $\mathbf{1 \mathbf { ~ m } ^ { \mathbf { 3 } }}$ & $\mathbf{1}$ liter \\
\hline CEM II 42.5 A-V & 556 & 556.00 \\
Sand 0.3/2.5 mm & 863 & 863.00 \\
Sand 0/0.5 mm & 288 & 288.00 \\
Filler (Dolomite powder) & 150 & 150.00 \\
Microsilica & 81 & 81.00 \\
Water & 247.0 & 247.00 \\
SIKA EVO 26 & 9.00 & 9.00 \\
SIKA AER S (10\%) & 2.00 & 2.00 \\
Fiber: & & \\
SAINT-GOBAIN & 0.00 & 0.00 \\
Total fibers: & & 2196.00 \\
Fibers \% & 0.00 & \\
Total: & 2196.00 & \\
\hline
\end{tabular}

Stress-displacement curve was obtained according to pull-out test (see Fig 2.2.1), where the forces converted to be stresses.

Figure 2.1.1. Pull-out test three stages. 


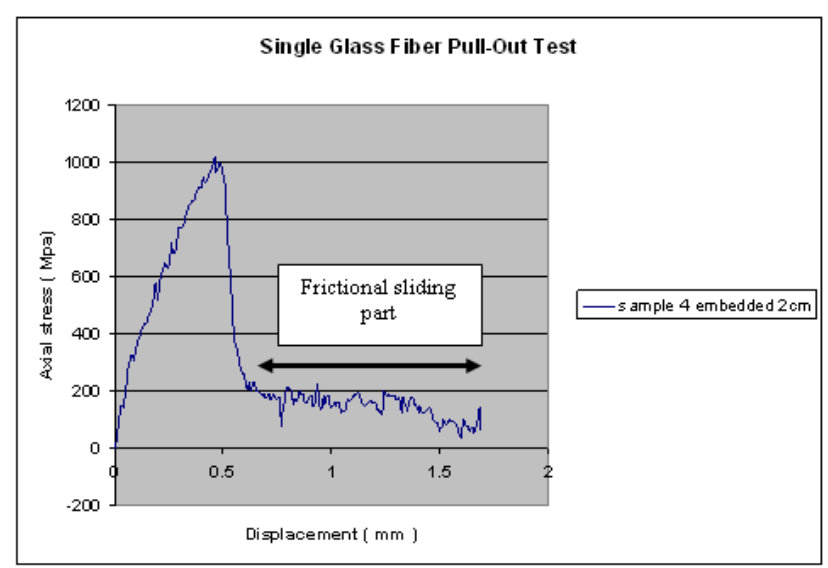

Figure 2.2.1. Stress-displacement curve of pull-out experimental test.

\subsection{Programming Simulations Pull-Out Test Results}

Various simulations are prepared for each expected friction coefficient $(0.1 ; 0.2 ; 0.3$ respectively), and different values of displacement within the experimental displacement domain of the frictional sliding part; therefore the axial stress of each displacement $(0.143 \mathrm{~mm} ; 0.403 \mathrm{~mm} ; 0.653 \mathrm{~mm} ; 0.903 \mathrm{~mm}$; $0.973 \mathrm{~mm}$, respectively) can be shown as the following:

Material properties are: (see Fig 2.3.1, 2.3.2)

Concrete matrix $\quad \mathrm{E}=30000 \mathrm{MPa}, v=0.2$

Glass fiber $\quad \mathrm{E}=70000 \mathrm{MPa}, v=0.2$

\section{Results and Discussion}

According to Figure 1.3, a finite element model is created of pull-out simulation, and the axial stresses distribution can be shown in Figures 2.3.1, 2.3.2, therefore the determination the axial stress value for each case can be obtained, such as in Figure 2.3.2, where the maximum axial stress is obtained successfully for an assumed friction coefficient Fri $\mathrm{F}_{(\mathrm{GF} . \mathrm{C})}=0.2$ and displacement $=0.143 \mathrm{~mm}$.

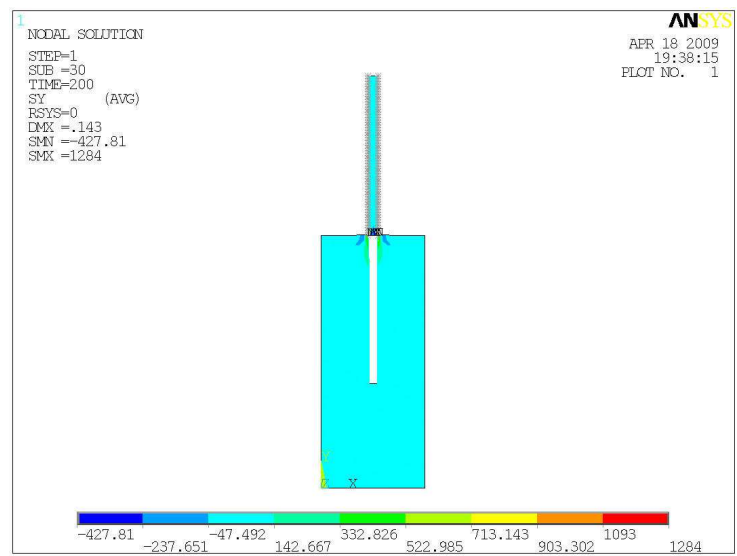

Figure 2.3.1. Axial stress distribution of pull-out simulation.

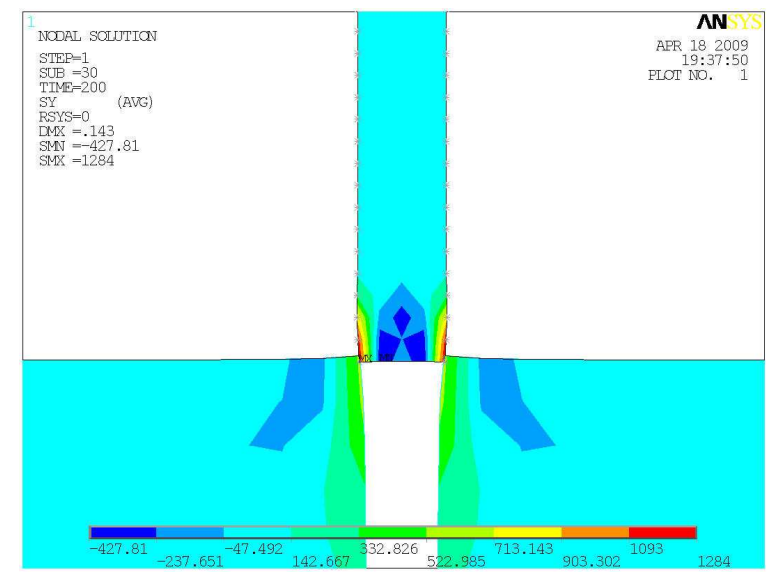

Figure 2.3.2. Axial stresses distribution of pull-out simulation for assumed friction coefficient Fri ${ }_{(G F . C)}=0.2$ and displacement $=0.143 \mathrm{~mm}$.

Repeating similar steps for other situations gives results as shown in Table 3.1.

Table 3.1. Maximum axial stresses of various pull-out single glass fiber simulations with expected displacements and various friction coefficient values.

\begin{tabular}{ccccccc}
\hline \multicolumn{2}{c|}{ Displacement (mm) } & 0.143 & 0.403 & 0.653 & 0.903 & 0.973 \\
\multicolumn{2}{c}{ Experimental stress (MPa) } & 72.689 & 87.624 & 151.363 & 123.479 & 161.320 \\
& Friction coefficient & 7.044 & 33.823 & 28.122 & 80.936 & 40.325 \\
Simulation stress & 0.1 & 72.725 & 135.600 & 99.170 & 132.830 & 142.285 \\
$(\mathrm{MPa})$ & 0.2 & 134.620 & 251.900 & 170.240 & 291.500 & 275.156 \\
\hline
\end{tabular}

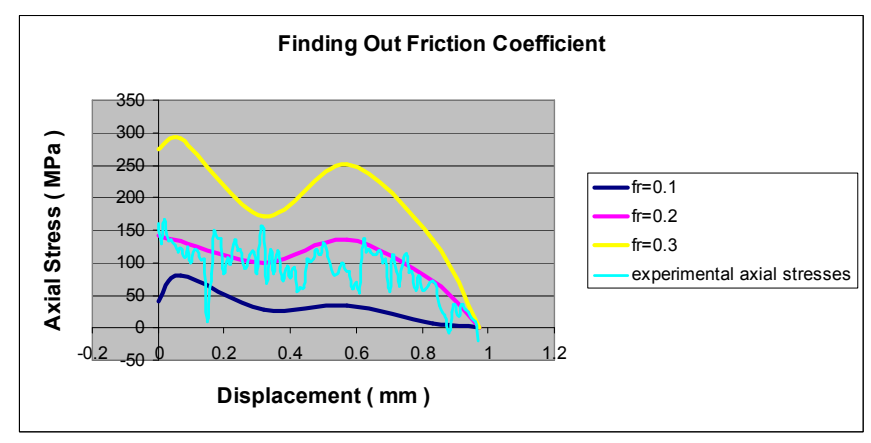

Figure 3.1. Conformity curves to find the value of friction coefficient between glass fiber and the concrete.
Using these final results of the maximum axial stresses of the various cases of displacements and friction coefficient as well as the experimental stress values as shown in Table 3.1, and matching these results, final curves can be obtained as shown in Figure 3.1.

Figure 3.1 shows three different curves for three different expected values of friction coefficient $(0.1 ; 0.2 ; 0.3$ respectively) predicted from single glass fiber pull-out test simulations and the experimental curve of real axial stresses values obtained from research experiment data base. The comparison of the experimental curve with the simulation curves leads to predicting the real value of the friction coefficient Fri (GF.C) $_{\text {to }}$ to around 0.2, the experimental curve is closer to the simulation curve of friction factor $=0.2$, therefore 
the prediction value of friction coefficient between the glass fiber and the concrete is 0.2 .

$$
\operatorname{Fri}_{(G F . C)}=0.2
$$

\section{Conclusions}

- Predicted value of friction coefficient between glass fiber and the concrete equal to 0.2 .

- Pull-out test is divided into three stages according to debonding level at the interface of glass fiber and the concrete.

- Sliding part of experimental pull-out test represents the stage which must be used to find the expected value of friction coefficient.

- Programming simulations of pull-out test were very important to determine the expected ranges of friction coefficient values.

- Evaluation of bonding forces between glass fiber and the concrete is related directly with the value of friction coefficient between these two building construction materials.

\section{References}

[1] Amjad Khabaz, "Non-Metallic Fiber Reinforced Concrete", LAP LAMBERT Academic Publishing, 2014, ISBN 978-3-659-50914-8.
[2] Amjad Khabaz, "Dynamical Analysis of Non-Metallic (Glass, Carbon) Fiber Reinforced Concrete under the Influence of Vibration", International Journal of Composite Materials, Vol. 3No.6, 2013, pp. 174-180. doi: $10.5923 / \mathrm{j} . \mathrm{cmaterials.20130306.06.}$

[3] A.Krasnikovs, A. Khabaz, G.Shahmenko and V.Lapsa. GLASS AND CARBON FIBER CONCRETE MICROMECHANICAL AND MACROMECHANICAL PROPERTIES // Sc. Proceedings of Riga Technical University, Transport and Engineering, 6 Vol. 28, Latvia, 2008, p.132-141.

[4] Krasņikovs A., Kononova O., Khabaz A., Vība J. Fiberconcrete Non-Linear Fracture Control through Fresh Concrete Flow Numerical Simulation // Journal of Vibroengineering. Vol.12, Iss.2. (2010) pp 149-160.

[5] Fachvereinigung Faserbeton e.V.-. Glassfibre reinforced concrete: practical design and structural analysis // Beton-Verl., 1995.

[6] D. Hull and T. W. Clyne. An Introduction to Composite Materials // Second Edition,1996, Cambridge University Press.

[7] RILEM Symposium 1978, Testing and Test Methods of Fibre Cement Composites, edited by N. R. Swarmy, The Construction Press, Lancaster, 1978.

[8] S. Frondistou-Yannas. Flexural strength of concrete with randomly oriented glass fibers // Magazine of concrete research : Vol. 29, No. 100 : September 1977. 